\title{
Functional illiteracy and developmental dyslexia: looking for common roots. A systematic review
}

\author{
Réka Vágvölgyi (i) - Kirstin Bergström (1) Aleksandar Bulajić • Maria Klatte (ib) \\ Tânia Fernandes (D) Michael Grosche (D) Falk Huettig • Jascha Rüsseler (D) \\ Thomas Lachmann $(\mathbb{D}$
}

Received: 26 August 2020/Revised: 3 December 2020/ Accepted: 22 December 2020/Published online: 19 February 2021

(C) The Author(s) 2021

\begin{abstract}
A considerable amount of the population in more economically developed countries are functionally illiterate (i.e., low literate). Despite some years of schooling and basic reading skills, these individuals cannot properly read and write and, as a consequence have problems to understand even short texts. An often-discussed approach (Greenberg et al. 1997) assumes weak phonological processing skills coupled with untreated developmental dyslexia as possible causes of functional illiteracy. Although there
\end{abstract}

Supplementary Information The online version contains supplementary material available at https://doi.org/10.1007/ s41809-021-00074-9.

R. Vágvölgyi · K. Bergström · A. Bulajić ·

M. Klatte · T. Lachmann $(\bowtie)$

Cognitive and Developmental Psychology Unit, Centre

for Cognitive Science, University of Kaiserslautern,

Kaiserslautern, Germany

e-mail: lachmann@sowi.uni-kl.de

R. Vágvölgyi

e-mail: reka.vagvoelgyi@ sowi.uni-kl.de

K. Bergström

e-mail: kirstin.bergstroem@sowi.uni-kl.de

A. Bulajić

e-mail: alexander.buljic@ @owi.uni-kl.de

M. Klatte

e-mail: klatte@rhrk.uni-kl.de

A. Bulajić

Chair of Andragogy, Faculty of Philosophy, University of

Belgrade, Belgrade, Serbia is some data suggesting commonalities between low literacy and developmental dyslexia, it is still not clear, whether these reflect shared consequences (i.e., cognitive and behavioral profile) or shared causes. The present systematic review aims at exploring the similarities and differences identified in empirical studies investigating both functional illiterate and developmental dyslexic samples. Nine electronic databases were searched in order to identify all quantitative studies published in English or German. Although a broad search strategy and few limitations were applied, only 5 studies have been identified adequate from the resulting 9269 references. The

\footnotetext{
T. Fernandes

Faculdade de Psicologia, Universidade de Lisboa, Lisbon,

Portugal

e-mail: tpfernandes@psicologia.ulisboa.pt

M. Grosche

Institute of Educational Research, University of

Wuppertal, Wuppertal, Germany

e-mail: michael.grosche@uni-wuppertal.de

F. Huettig

Max Planck Institute for Psycholinguistics, Nijmegen,

The Netherlands

e-mail: falk.huettig@mpi.nl

F. Huettig

Centre for Language Studies, Radboud University,

Nijmegen, The Netherlands
} 
results point to the lack of studies directly comparing functional illiterate with developmental dyslexic samples. Moreover, a huge variance has been identified between the studies in how they approached the concept of functional illiteracy, particularly when it came to critical categories such the applied definition, terminology, criteria for inclusion in the sample, research focus, and outcome measures. The available data highlight the need for more direct comparisons in order to understand what extent functional illiteracy and dyslexia share common characteristics.

Keywords Illiteracy $\cdot$ Low literate $\cdot$ Adult basic education $\cdot$ Dyslexia $\cdot$ Reading $\cdot$ Comprehension

\section{Introduction}

Reading and writing are fundamental for acquiring other key competencies for lifelong learning (Council 2018), which are necessary for participation in the society. Large-scale studies have shown that, the level of literacy of many adolescents and adults are not sufficient to participate fully in everyday life (OECD 2013). For example, in the recent PIAAC Survey of Adult Skills (OECD 2019), 19.8\% of the adult population (16-65 years) from 39 countries and economies could read and locate only single pieces of information in simple texts. In France, the Information and Daily Life Survey (IVQ: Information et Vie Quotidienne, Jeantheau 2015) showed that in $2011,11.0 \%$ of the adults (16-64 years; 4.3 million) performed poorly in at least one of the three domains investigated: reading aloud, reading comprehension, and writing. In Germany, the Level One Survey showed that $12.1 \%$ (LEO 2018, Grotlüschen et al.

\footnotetext{
J. Rüsseler

Department of Psychology, University of Bamberg,

Bamberg, Germany

e-mail: jascha.ruesseler@uni-bamberg.de

J. Rüsseler

Bamberg Graduate School of Affective and Cognitive Sciences (BaGrACS), University of Bamberg, Bamberg, Germany

T. Lachmann

Facultad de Lenguas y Educación, Universidad Nebrija, Madrid, Spain
}

2019) of the German-speaking adults (18-64 years; 6.2 million) are not able to read and write texts, even if they are brief.

This phenomenon of limited reading and writing skills has been termed as functional illiteracy (BarKochva et al. 2019), which impedes people from effortlessly accomplishing otherwise simple tasks such as filling out a job application, reading a medicine label, or participating successfully in vocational training programs. According to the UNESCO (2006) and the World Literacy Foundation (Cree et al. 2012), those with functional illiteracy are more likely to be left behind and receive less political, cultural, social, and economic benefits. Therefore, functional illiteracy is a societal problem with major (economical) implications not only for those suffering from it but also for the societies to which they belong. In more economically developed countries, the costs resulting from functional illiteracy (e.g., welfare payments and burden on the health systems), amount to about $2 \%$ of the Gross Domestic Product, i.e., 362 billion dollars in the US and 68 billion in Germany (World Literacy Foundation 2015). As a first step, it is critical to better understand the predictors of functional illiteracy, as well as the most effective measures for prevention and intervention.

Socioeconomic and sociodemographic factors as well as individual factors (cognitive, emotional and motivational) have been identified in the literature (see, e.g., Vágvölgyi et al. 2016, for review) to affect-isolated or in combination-literacy acquisition in childhood (e.g., Hemmerechts et al. 2016) as well as literacy proficiency in adulthood (e.g., OECD 2019). For instance, adults with low literacy skills were found to be more often older than 45 years, male, not or low educationally qualified, not native speakers, and more often unemployed (Grotlüschen et al. 2019). Furthermore, disadvantages in family background (e.g., low economic security, neglect and disinterest), school experience (e.g., social shame, punishment for failure; Döbert and Hubertus 2000; Nickel 2007), and medical history (e.g., chronical disease, brain damage, uncorrected impaired vision and hearing; Ardila et al. 2010) were found to be associated with low literacy skills. Above all, due to socioeconomic and sociodemographic factors, low literacy tends to be passed from one generation to the next (Grotlüschen and Riekmann 2011; Nickel 2007). 
Besides these factors, developmental dyslexia could be also considered as a potential precursor of functional illiteracy (e.g., Greenberg et al. 1997). Developmental dyslexia is characterized by significant and persistent difficulties in learning to read, expressed at behavioral level by individual reading accuracy, fluency, and comprehension that is markedly below what would be expected for chronological age, general cognitive development, and appropriate education, resulting in significant impairment in the individual's academic functioning (6A03.0, World Health Organization 2019).

Research on adults with low literacy revealed higher prevalence rates of developmental dyslexia than in the general population. For example, in the USA, $48 \%$ of the English native speaking ABE students (Adult Basic Education; literacy programs for low-literate adults, offered by community colleges and adult education centers) reported a learning disability in childhood (MacArthur et al. 2010), while another study (Gottesman et al. 1996) diagnosed 33\% of their literacy program participants with developmental dyslexia. In the LEO 2018 study (Grotlüschen et al. 2019, 2020), the prevalence rate of developmental dyslexia was more than twice as high in the group of low literate adults when compared to the group of skilled readers ( 7.0 vs. $2.9 \%$, Heilmann 2020 ).

In the current review, we aim to examine whether and to what extent functional illiteracy and developmental dyslexia show common patterns of behavioral and cognitive deficits. Our research strategy was to systematically review studies that investigated putative deficits that were shared between these two groups. Given that there is substantial knowledge about effective interventions in dyslexia, the present review can provide insights, which, in turn, could have substantial impact on development of training programs in functional illiteracy. Before describing the systematic review, we will focus on the definitions of functional illiteracy and developmental dyslexia, as well as provide a general overview on studies that looked at behavioral and cognitive profiles in the groups separately.

Definitions and diagnostic criteria of functional illiteracy

UNESCO first recognized functional illiterate persons in 1978 and described them as individuals who "[...] cannot engage in all those activities in which literacy is required for effective functioning of his group and community and also for enabling him to continue to use reading, writing, and calculation for his own and the community's development" (UNESCO 1979, p. 183). Since then, several conceptual and operationalized definitions appeared, however, the applied criteria to define and the assessment tools to identify the functional illiterate or low literate population vary between countries (e.g., France vs. Germany) and methodologies (e.g., large-scale vs. experimental design).

For example, the IVQ study uses the term illiterate, or individual in the situation of illiteracy (literal translation of les personnes en situation d'illettrisme), for adults who attended school for at least 6 years but who did not achieve mastery in reading, writing, and other basic skills (e.g., oral communication, logical reasoning, comprehension), which would allow them to be autonomous in daily life (Jeantheau 2015). The LEO studies (Grotlüschen et al. 2019; Grotlüschen and Riekmann 2011), in contrast, do not take school attendance into account in the definition of functional illiteracy. Instead, they use the term low literate adults to refer to adults that are able to read and write letters and/or words and/or isolated sentences, but not texts, even if texts are short, which has negative consequences, as aforementioned, on these adults' abilities to deal with everyday requirements.

The experimental studies, which tested adults with low (or no) literacy skills usually recruit their samples from basic education or literacy/alphabetization courses for adults. Therefore, the terms adult basic education students or adult literacy students are often adopted. These studies often apply diagnostic reading tests and grade equivalence scores when selecting their samples, however, they differ from country to country. In experimental studies with native German speakers, different decoding and comprehension measures are often used with the cut-off of an average 4thgrade student to differentiate people with low literacy skills from literates (e.g., Boltzmann and Rüsseler, 2013; Grosche 2012). In studies with native French speakers (e.g., Eme et al. 2010), the average 3rd-grade level with the same aim was employed. To the best of our knowledge, none of these studies used assessment tools, which were explicitly developed and normed on low literate adults. This is not the case for studies conducted in the USA, where, in contrast, 
standardized tests for adults with low literacy skills are available (e.g., Test of Adult Basic Education, TABE: CTB/McGraw-Hill, 2008) and commonly used in research as well as in practice (e.g., Barnes et al. 2017; MacArthur et al. 2012; US Department of Education 2016).

Established standards of defining and identifying functional illiteracy would be essential for scientific studies, however, the great variety of terms and definitions among disciplines and societies makes it hard to compare their results. Regarding terms, low literate seems to prevail over the term functional illiterate (e.g., Grotlüschen et al. 2019), however, as the latter term describes more specific the group of our interest, we will use it throughout the article. Regarding definition, at least, there is some agreement (see Vágvölgyi, 2018) that functional illiterate individuals are adults who-despite at least a few years of education-do not possess a minimum literacy level required for adequate participation in their respective society. For the present study, we will use this broad definition.

Behavioral and cognitive profiles associated with functional illiteracy

In functional illiteracy research, among the cognitive precursors of literacy acquisition, phonological processing has received the biggest attention. Functional illiterate individuals have lower performance in phonological processing and decoding tasks than literate adults and reading-level matched children, on both transparent (German: Grosche 2012; Grosche and Grünke 2011) and opaque orthographies (English and French, respectively: Eme et al. 2014; Thompkins and Binder 2003). It was found that the reading and spelling performance of functional illiterate individuals can be better predicted by their performance in phonological awareness tasks than by the number of completed school years (Landgraf et al. 2012), their vocabulary knowledge, or their oral language comprehension skills (Eme et al. 2014). Some results (e.g., Greenberg et al. 2002) suggest that functional illiterate individuals compensate for their phonological processing and decoding deficits by focusing on orthographic strategies (direct recognition of frequent words without alphabetic decoding, directly from the orthographic lexicon; cf. Coltheart 2005) and on context (Binder et al. 2007). However, this can be only partially successful, since phonological skills are an essential prerequisite for the construction of the orthographic lexicon (Share 1995; Ziegler et al. 2014). Given these findings, a systematic reshaping of the early phonology-oriented (alphabetic) stage (e.g., Frith 1986) appears to be inevitable in the literacy courses targeting functional illiterate individuals.

The finding of phonological processing deficits in functional illiterate individuals is supported by brain research (see Huettig et al. 2018, for a review). In a Diffusion Tensor Imaging (DTI) study (Boltzmann et al. 2017), relative to non-impaired readers, German functional illiterate individuals showed reduced grey matter in reading-relevant temporo-parietal brain areas, known to be involved in the phonological analysis of words and in alphabetic reading and writing (grapheme-phoneme conversion) during literacy acquisition (e.g., Pugh et al. 2000). Interestingly, these structural differences were no longer evident after functional illiterate individuals attended the ninemonth intensive literacy course with a strong phonological component (systematic teaching of the sound structure and grapheme-phoneme correspondences) (AlphaPlus; Rüsseler et al. 2012).

Given that people who are primarily illiterate (i.e., people who have never attended formal education or schooling) show poor phonological skills (Dehaene et al. 2010), it might be the case that these deficits are cause or consequence of reduced and suboptimal reading experience. This question is hitherto open (see Huettig et al. 2018, for a review).

The whole pattern of deficits in phonological processing and decoding is also found in children with developmental dyslexia (Hulme and Snowling 2009; Klatte et al. 2013; Swanson and Hsieh 2009) and is seen, by a number of authors, as representing the universal cause for problems in learning to read and write (e.g., Snowling 2001). Therefore, a further explanation for functional illiteracy could be an undiagnosed or untreated developmental dyslexia in childhood (e.g., Greenberg et al. 1997).

The overlap between functional illiteracy and developmental dyslexia

Besides the already mentioned phonological processing and decoding deficits, experimental and neuropsychological studies suggest, however, that further 
deficits may contribute to problems in learning to read and write as well, such as visual processing deficits (e.g., Becker et al. 2005; Lovegrove et al. 1986; see Stein 2018a, b, for a review), basic auditory (Christmann et al. 2015; Witton and Talcott 2018) or temporal processing deficits (Groth et al. 2011; Steinbrink et al. 2012; Tallal 1980; see Farmer and Klein 1995 or Stein 2018a, b, for a review) or an automatization deficit (Nicolson and Fawcett 2018, 1990), and that there are subgroups of developmental dyslexia regarding the pattern of underlying deficits (Heim et al. 2008; Lachmann et al. 2005; Ramus et al. 2003; Steinbrink et al. 2014). Several of these deficits were also found in functional illiterate individuals, which led to the suggestion that developmental dyslexia might be a possible cause for functional illiteracy (see Vágvölgyi et al. 2016, for a review).

The Functional Coordination framework of reading acquisition (Lachmann 2002, 2018) could account for both developmental dyslexia and functional illiteracy (Bulajić et al. 2019). According to this model, reading acquisition develops along four stages. The learner recruits preexisting functions (e.g., phonological skills, grapheme awareness), a reading-specific procedure is built through optimal modification and finetuned coordination of skills and strategies, and this is automatized through years of practice to become a cognitive skill (Van Leeuwen and Lachmann 2004). Thus, individuals who are functionally illiterate may not have properly completed the coordination stage and/or failed to reach the automatization of the reading procedure (Nicolson and Fawcett 1990, 2018), which would hinder text comprehension, as they would need to invest most of their available cognitive resources in decoding, i.e., reading words (Bulajić et al. 2019).

Research question and assumptions

Even though developmental dyslexia has been considered for decades a possible cause of functional illiteracy in adulthood (e.g., Greenberg et al. 1997), studies were focusing mostly on the prevalence of developmental dyslexia among the low literate population but less on the commonalities in their cognitive profiles. Empirical studies assessing both groups simultaneously are lacking. In the present systematic review, we aim to collect, summarize and evaluate available studies (including "grey" literature) that include both functional illiterate and developmental dyslexic groups. Our research question is: What are the similarities and differences between functional illiteracy and developmental dyslexia? Although, having a very broad research question, without any restriction (e.g., for specific outcome measures), we assume to find only a small number of studies systematically comparing functional illiteracy and developmental dyslexia.

\section{Methods}

To ensure the high standards of reporting, the PRISMA guidelines (Moher et al. 2009) have been followed throughout our systematic review. The review protocol was submitted in November 2019 with the International Prospective Register of Systematic Reviews (PROSPERO: CRD42020156766, Lachmann et al. 2020).

Eligibility criteria

Here, we aim to identify all available studies including both functional illiterate (i.e., low literate) and developmental dyslexic populations. The functional illiterate target population was defined as adults (i.e., between 16 and 65 years old), with some years of education (i.e., attended school to learn to read and write), and with low literacy skills (i.e., lower level than would be expected from the general population). Therefore, those below 16 years of age and primary illiterate (who never attended school) were not included as functional illiterate. The developmental dyslexic target population was defined as those (children or adults) with either a clinical diagnosis by professionals or identified retrospectively based on related symptoms or received diagnosis in childhood (self-report). Thus, we also excluded studies that included participants with general cognitive impairments (i.e., IQ below 70; limited to studies in which a professional performed the assessment for dyslexia).

All studies included were published in English or German without restrictions of publication year. To eliminate publication biases and increase the number of potentially relevant papers, unpublished ("grey") literature with original quantitative data was also considered (Table 1). 
Table 1 List of eligibility criteria

\begin{tabular}{|c|c|c|}
\hline & Inclusion criteria & Exclusion criteria \\
\hline \multicolumn{3}{|l|}{ Population } \\
\hline $\begin{array}{l}\text { Functional } \\
\text { illiterate } \\
\text { population }\end{array}$ & $\begin{array}{l}\text { Individuals between } 16 \text { and } 65 \text { years old with some } \\
\text { years of education in childhood, adolescence or } \\
\text { adulthood and with low literacy skills }\end{array}$ & $\begin{array}{l}\text { Children (below } 16 \text { years old) and primary illiterates, } \\
\text { i.e., adults (16-65 years old) without any formal } \\
\text { education }\end{array}$ \\
\hline $\begin{array}{l}\text { Developmental } \\
\text { dyslexic } \\
\text { population }\end{array}$ & $\begin{array}{l}\text { Individuals (children, adolescence and adults) with } \\
\text { clinical diagnosis or self-report of developmental } \\
\text { dyslexia }\end{array}$ & $\begin{array}{l}\text { Individuals with an IQ below } 70 \text { (restricted only to } \\
\text { those studies where a professional carried out the } \\
\text { assessment for dyslexia) }\end{array}$ \\
\hline Publication type & $\begin{array}{l}\text { Published articles, dissertations, reports/book } \\
\text { chapters with original quantitative data }\end{array}$ & $\begin{array}{l}\text { Reviews, comments, editorials, manuals, guidelines, } \\
\text { qualitative studies }\end{array}$ \\
\hline $\begin{array}{c}\text { Publication } \\
\text { language }\end{array}$ & English, German & Other languages \\
\hline
\end{tabular}

Search strategy

We followed a broad search strategy due to the heterogeneity of terms and definitions, as well as our assumption about the scarce research, which directly or indirectly investigated the link between functional illiteracy and developmental dyslexia. The studies were collected from nine bibliographic databases on November 25th 2019: Dimensions, ERIC, JSTOR, Open Grey, ProQuest, PubMed, PubPsych, Scopus, and Web of Science. Moreover, to detect unpublished papers, two queries were circulated (in the German scientific community: Educational and Developmental Psychology Sections of the German Psychological Society, and in the international scientific community: Society for the Cognitive Science of Culture).

The search terms were divided into two sets connected with the AND-operator: functional illiteracy and developmental dyslexia, respectively. As aforementioned, standards to define people with functional illiteracy have not yet been established and terms are used differently among disciplines and societies: in Europe, the terms "functional illiterate" and "low literate" are used, while in the US the terms "adult basic education student" or "adult literacy student" are most common. Given this heterogeneity, a wide range of search terms has been collected to describe the functional illiterate population. The search terms were adjusted to the requirements and specifications of the databases, as presented in Table 2.
Screening

After removing duplicates, search results were screened in three phases. Phase 1: in a pre-screening, studies from irrelevant publication types were identified and excluded based on their titles; these included bibliographies, collections of abstracts, reviews, metaanalyses, comments, commentaries, manuals, and guidelines. Phase 2: each record was reviewed by two out of a total of five independent coders, whom, based on the titles and abstracts, decided whether a record fulfilled all inclusion criteria ("maybe" or "yes", i.e., requires full-text screening) or whether it met at least one of the exclusion criteria ("no", i.e., exclusion). Phase 3: two independent coders reviewed the full text of the remaining records. They decided whether the full text fulfilled all inclusion criteria. In Phase 2 and 3, coders documented the reason for exclusion, discussed disagreements and made resolutions by consensus.

\section{Quality assessment}

The methodological quality of the studies surviving the screening procedure was assessed. For quality assessment of the studies, the Quality Assessment Tool for Reviewing Studies with Diverse Design (QATSDD, Sirriyeh et al. 2012) was identified by the authors as fitting best to the experimental and correlational study designs typically used in the field of literacy research. The 16-item rating system was developed for assessing the reporting and methodological quality of heterogeneous study designs 
Table 2 List of search terms applied on titles and abstracts

\begin{tabular}{|c|c|c|}
\hline & English & German \\
\hline $\begin{array}{r}\text { Functional } \\
\text { illiteracy }\end{array}$ & $\begin{array}{l}\text { Illitera* OR analphabet* OR "functional *litera*" OR } \\
\text { "semi-*litera*" OR "late-literate*" OR "ex- } \\
\text { *literate*" OR "quasi-*litera*" OR "partial *litera*" } \\
\text { OR "adult basic education" OR "adult litera*" OR } \\
\text { "low litera*" OR "poor litera*" OR "poor read*" }\end{array}$ & $\begin{array}{l}\text { Analphabet* OR grundbildung OR erwachsenenbildung } \\
\text { OR alphabetis* OR literalität OR "gering litera*" }\end{array}$ \\
\hline $\begin{array}{l}\text { Developmental } \\
\text { dyslexia }\end{array}$ & $\begin{array}{l}\text { Dyslexi* OR dyslectic* OR "learning disab*” OR } \\
\text { "learning disorder" OR "reading disorder" OR } \\
\text { "reading disab*" OR "reading difficult*" OR } \\
\text { "spelling disab*" OR "spelling disorder" OR } \\
\text { "spelling difficult*" }\end{array}$ & $\begin{array}{l}\text { Legasthen* OR dyslexi* OR dyslektiker OR } \\
\text { lernbehinderung* OR lernschwäche* OR lernstörung* } \\
\text { OR lernschwierigkeit* OR "lese-rechtschreib*" OR } \\
\text { "gering* lese-rechtschreibleistung*" OR "schwach* } \\
\text { lese-rechtschreibleistung*" OR leseschw* OR } \\
\text { lesestör* OR lesedeficit OR "schwach* lese*" OR } \\
\text { "gering* lese*" OR "unterdurchschnittlich* lese*" } \\
\text { OR rechtschreibstörung* OR rechtschreibschw* OR } \\
\text { "schwach* rechtschreib*" OR "gering* } \\
\text { rechtschreib*" OR "unterdurchschnittlich* } \\
\text { rechtschreib*" }\end{array}$ \\
\hline
\end{tabular}

(qualitative, quantitative and mixed methods). Two independent coders assessed the quality of the eligible papers using the QATSDD. Discrepancies were discussed and resolved by consensus.

\section{Results}

Results of the search

From the initially identified 9269 hits (databases and queries), 2170 records were removed because of duplication. From the remaining records, 1397 were excluded because of the publication type (Phase 1). The abstracts and titles of the remaining 5702 studies were screened by two independent coders (Phase 2). The 43 studies selected (agreement between the coders in Phase $2=96.84 \%$ ) were read in full and were screened by two independent coders (Phase 3 ). Among them, 37 studies were excluded. Two of them (Tal et al. 1994; Mellard and Patterson 2008) were discussed more intensively because they did include quantitative data and both groups of interest. However, the functional illiterate sample in Tal et al. (1994) included adults and children (the latter was an exclusion criterion) without disentangling both groups and Mellard and Patterson (2008) did not provide the absolute level of reading and writing skills of the participants. Therefore, these studies were not considered further. Finally, six studies were identified as fitting to our research question and criteria (agreement between coders in Phase $3=95.35 \%$, Cohen's $\kappa=0.83$ ). Given that one record (Rüsseler et al. 2011) was part of a dissertation published later (Boltzmann 2014), this dissertation was not considered as a separate record. In total, five papers were eligible for synthesis, data extraction (Fig. 1, Tables 3, 4) and quality assessment.

Narrative synthesis of the studies

The five studies were selected turned out to be heterogeneous. It is clear that in what regards the definition and terminology adopted, there is no agreement. Our definition of functional illiterate included all adults without the necessary literacy skills expected from the general population, despite a few years of education, no matter when in their lifetime they received this (literacy) education. This applies for at least one sample in all of the five eligible studies. Note, however, that our definition might not be consensual among the studies included in the present work. Those four studies in which the term "functional illiteracy" was not adopted, may not agree with this terminology, in particular, if literacy instruction was held during adulthood. We, therefore, summarize the five studies in two subsections, considering whether literacy instruction occurred in childhood (Table 3) or in adulthood (Table 4). The summaries are following the same structure: first, the 


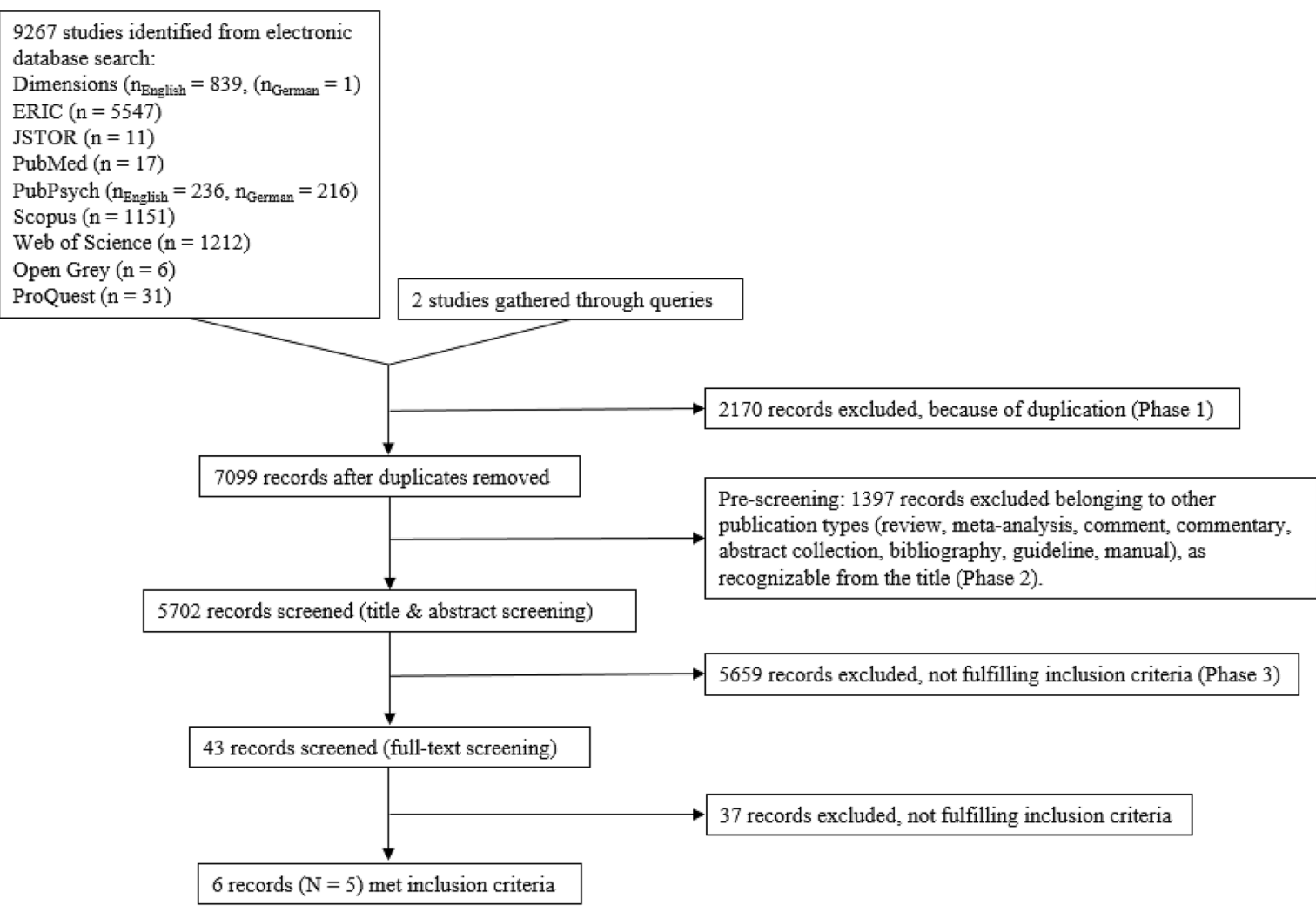

Fig. 1 Flowchart of the systematic literature search and selection process

goal of the study with the necessary background information is described; second, the samples are listed with a special stress on the groups identified as functional illiterate and developmental dyslexic; then, the experimental tasks are reported detailed enough to facilitate the comprehension of the results; fourth, the main results are explained and finally, an implication is provided, whether the constructs share or do not share difficulties, indicating similarities or differences.

\section{Functional illiterate individuals with education in childhood}

Rüsseler et al. (2011) examined visual and auditory perceptual skills of functional illiterate adults in order to investigate whether their performance (and putative deficits) would be similar to those found in children with developmental dyslexia. With this aim, they examined five groups: (1-2) two groups of functional illiterate adults having German as their first language (recruited from adult basic education courses in
Germany) and two groups of skilled readers, one (3) matched in age, the other (4) matched in both age- and IQ to the functional illiterate groups, and (5) a group of primary school children previously diagnosed with developmental dyslexia matched in reading level to the functional illiterate individuals. Information on recruitment and selection criteria for participants' inclusion was not provided. The groups of functional illiterate and skilled readers differed on average in reading performance (i.e., decoding and reading speed). Perceptual skills were examined with the BrainBoy ${ }^{\circledR}$ computerized test, which consists of 8 visual and auditory judgment and discrimination tasks. Functional illiterate adults and children with developmental dyslexia did not significantly differ from each other in any task and they performed significantly worse than the two groups of literate adults. Rüsseler et al. (2011) concluded that given the similar performance between functional illiterate individuals and children with developmental dyslexia, perceptual training might be beneficial for functional illiterate individuals as it was previously reported for 


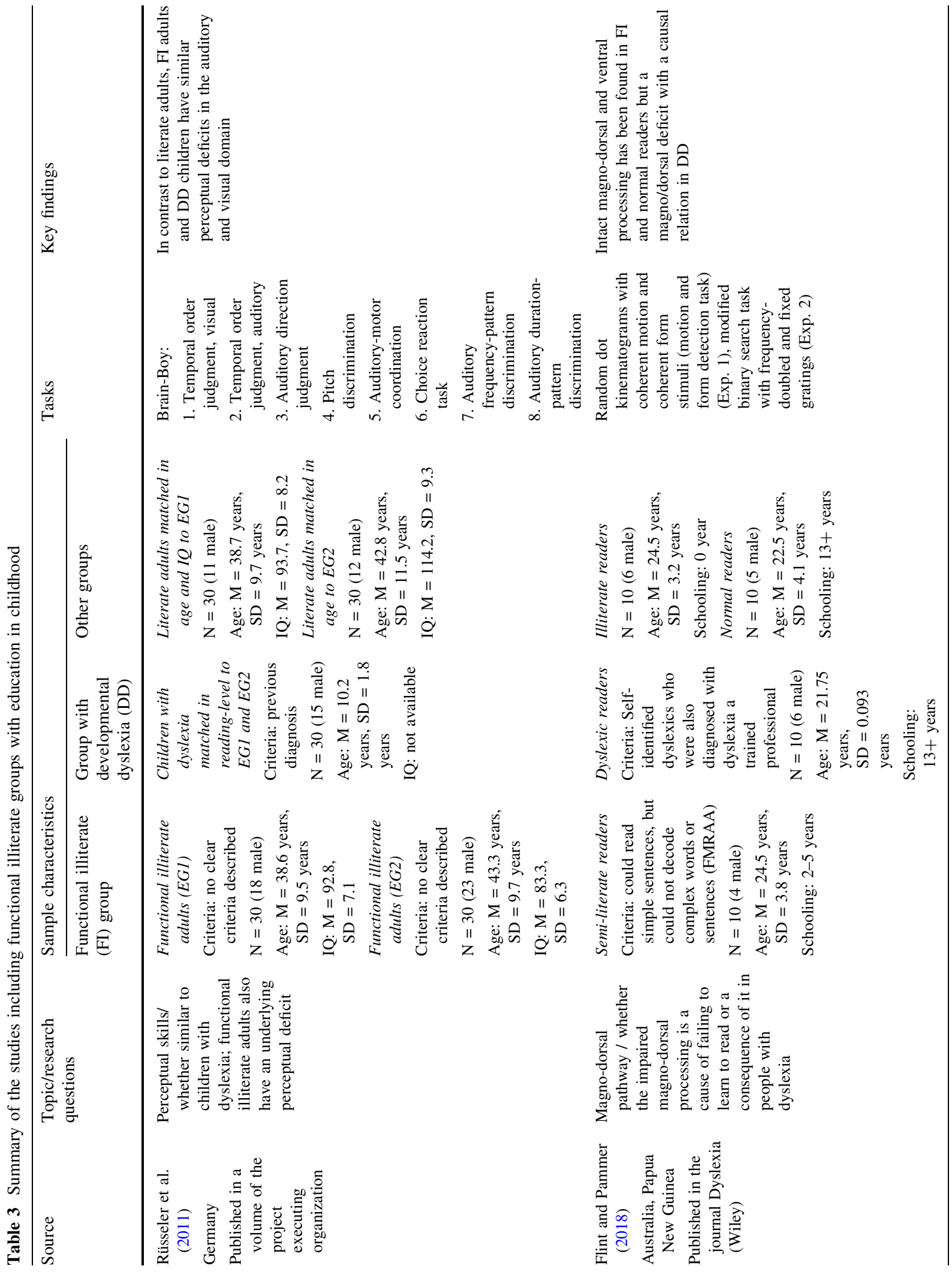




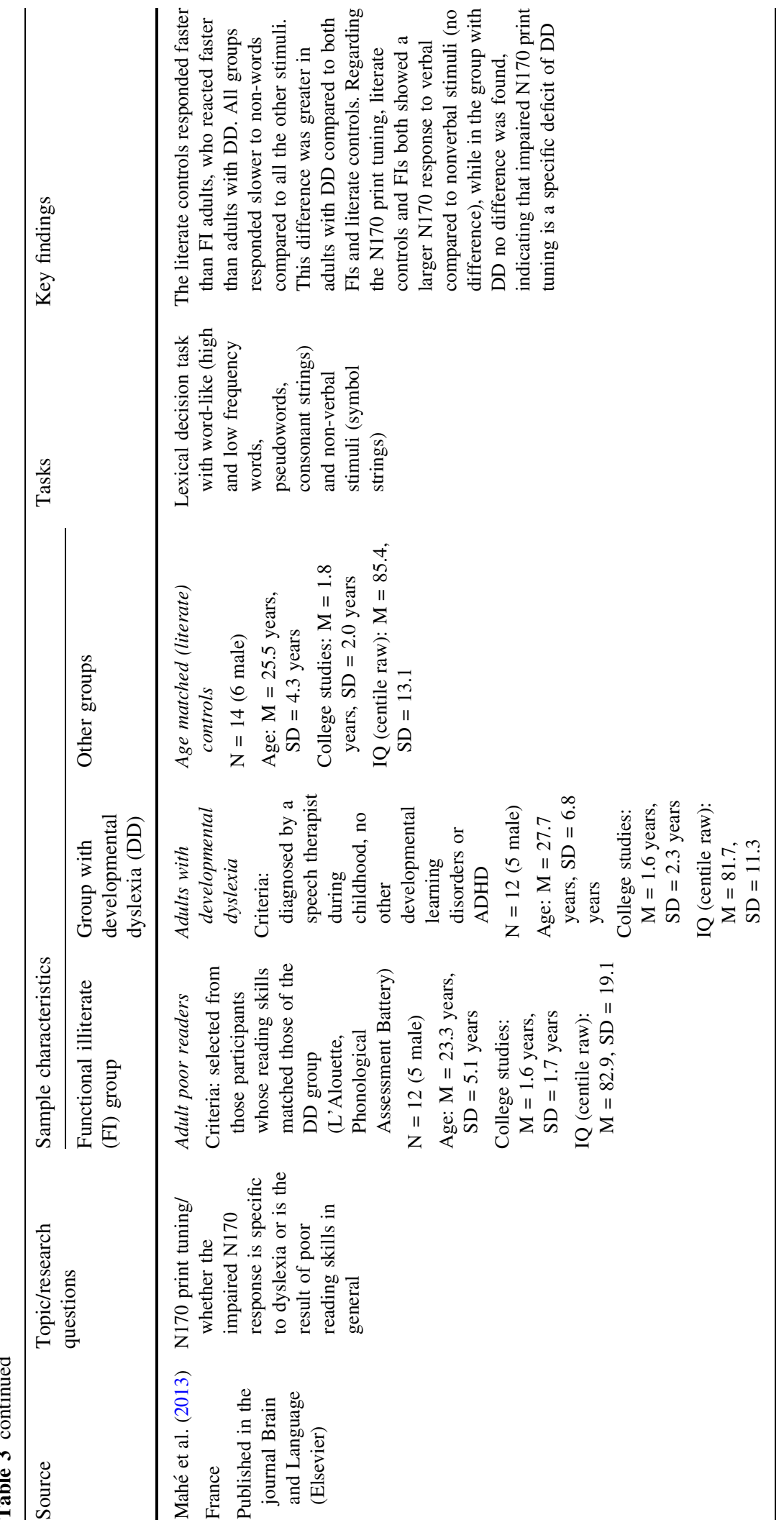




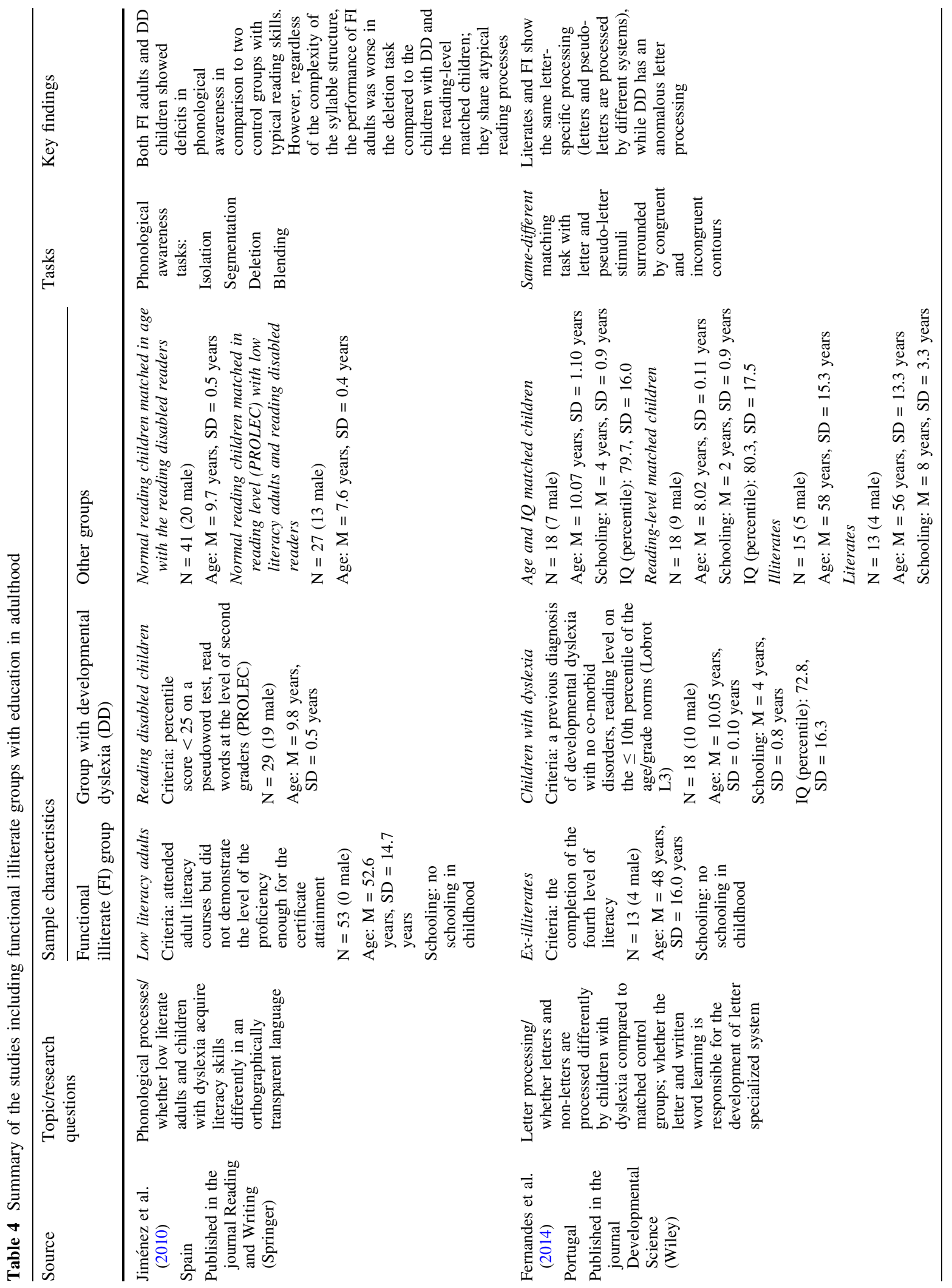


developmental dyslexia (Tewes and Steffen 2003). Regarding our research question, this pattern of results suggests that developmental dyslexia and functional illiteracy might share perceptual deficits.

Several studies have shown that adults with developmental dyslexia have poor performance in tasks underpinned by magno-dorsal pathway (e.g., Livingstone et al. 1991; Lovegrove et al. 1986), leading to the suggestion that this pathway plays a crucial role in reading acquisition and developmental dyslexia (see, Stein 2018a, b, for a review). On that basis, Flint and Pammer (2018) investigated whether the magnodorsal function is causally related to or a consequence of the reading disorder. In two experiments the following groups of participants were examined: (1) adults with former clinical diagnoses of developmental dyslexia, (2) illiterate readers, who were not able to identify even single letters, (3) functional illiterate individuals (termed as semi-literate readers), who could read simple sentences but could not decode complex words or sentences, and (4) skilled readers. The researchers adopted two tasks underpinned by magno-dorsal functioning: random dot kinematograms with either coherent motion or coherent form stimuli, and a binary search task with either frequency-doubled or fixed gratings. Adults with developmental dyslexia performed significantly worse in motion detection and were less sensitive to the frequency-doubled gratings than all other three groups. This pattern of results, where dyslexic readers differ even from the adults without any reading skills, suggests that magno-dorsal processing deficits are causally related with developmental dyslexia and are not just consequence of low reading skills. Moreover, the groups did not differ on form detection and sensitivity to fixed gratings, which are related with ventral visual processing. Regarding to our research question, it is clear that in magno-dorsal processing, dyslexic and functional illiterate individuals do not have this deficit in common.

Another line of research regards the readingspecific N170 event related potential (ERP) for written words (in comparison to non-orthographic stimuli; for a review see Maurer and McCandliss 2007), which is known to be associated with visual expertise for print (Maurer et al. 2005). A persistent deficit in left N170 print tuning has been found in developmental dyslexia (Mahé et al. 2012), however, it was not clear whether it is the result of poor reading skills or is specific to developmental dyslexia. Therefore, Mahé et al. (2013) examined three groups of native French speaking adults: (1) With former clinical diagnosis of developmental dyslexia, without comorbidity, (2) readinglevel matched functional illiterate individuals (termed as poor reading adults), and (3) age-matched skilled readers. When comparing the N170 induced by written material (words, non-words, consonant strings, and symbol strings, across categories) during a lexical decision task (i.e., participants must decide if the stimulus is a word or not) with that induced by symbol (non-letter) strings, skilled readers and functional illiterate individuals differed from each other and showed a larger N170 for written material than for symbol strings. Whereas dyslexic adults did not show any N170 difference between written material and non-letter symbols. Validating the classification of the three groups, skilled readers showed faster lexical decisions than functional illiterate individuals, which in turn, were faster than adults with developmental dyslexia. In all groups, the reaction times for nonwords were longer, compared to all the other stimuli, but dyslexic adults showed a greater difference than the other two groups. From these results, impaired N170 print tuning seems to be an electrophysiological correlate of a deficit specific in developmental dyslexia and not a mere reflection of low reading skills. Again, regarding to our research question, it seems that for neural tuning to print, adults with functional illiteracy and developmental dyslexia do not show a common impairment in the electroencephalography N170 print-tuning component.

\section{Functional illiterate individuals with education in adulthood}

As aforementioned, it is well known that reading skills are intrinsically related with phonological processing (e.g., Greenberg et al. 1997). Therefore, Jiménez et al. (2010) aimed to examine the phonological awareness skills of low literate and matched groups, namely (1) functional illiterate individuals (termed as low literacy adults) recruited from an adult basic education center, (2) primary school children with developmental dyslexia (termed as children with reading disabilities) performing below Percentile 25 in word and pseudoword reading at the level of Grade 2, and two groups of primary school children with typical reading skills, one (3) matched in age with the group of 
developmental dyslexia, and one (4) matched in reading-level with the functional illiterate and dyslexic groups. Phonological awareness was assessed with four tasks using items with different complexity in syllable structure: isolation, deletion, segmentation, and blending (Jiménez 1995). The performance of functional illiterate adults and children with developmental dyslexia was lower compared to the two groups of typical readers. Regardless of complexity in the syllable structure, functional illiterate adults were worse in phoneme deletion than children with developmental dyslexia and the reading-level controls. Thus, both the functional illiterate adults and the children with developmental dyslexia showed weak performance in phonological awareness, which were possibly related with their difficulties in reading acquisition. Note that, although the reading skills of functional illiterate adults was matched with one of the typical reading group, former still showed poor phonological awareness, suggesting that their results are not mere consequence of their (low) reading skills. Regarding our research question, this pattern of results suggests that developmental dyslexia and functional illiteracy share difficulties in phonological awareness.

Previous studies have examined the susceptibility of single letter and non-letter items to surrounding form-congruent or form-incongruent non-target flanker (cf. Van Leeuwen and Lachmann 2004) and showed that adult typical readers (Lachmann and van Leeuwen 2008a), primary school children, and children with developmental dyslexia (Lachmann and van Leeuwen 2008b) show similar congruency effects for non-letters (i.e., faster and/or more accurate target recognition, when it is surrounded by a congruent than an incongruent shape). However, these groups do differ on congruency effects found for letters, which depend on phonological decoding skills (non-word reading). Moreover, primary illiterate adults did not show differences in the congruency effects found for letter and non-letter targets (Lachmann et al. 2012). In order to examine the putative relationship between letter processing (relative to non-letter visual-control symbols) and developmental dyslexia, and directly compare congruency effects for surrounded letters between groups and individuals with different reading skills, Fernandes et al. (2014) examined the letter vs. non-letter congruency effects by (1) children with developmental dyslexia (with a former diagnosis of developmental dyslexia without comorbidity and with reading level below Percentile 10 for their grade/age in a silent reading comprehension test, TIL: Sucena and Castro 2008), recruited from the Dyslexia Unit of a Portuguese university, (2) age and (3) reading-level matched control children, (4) illiterate adults (without literacy instruction), (5) functional illiterate individuals (termed as ex-illiterate), who completed the final level of an alphabetization course and (6) schooled literate adults. All participants were native Portuguese speakers and the adult groups were matched in age, sex, socioeconomic, cultural, and residential backgrounds. All, except children with developmental dyslexia showed a differential congruency effect in a same-different classification task: present for nonletters, absent for letters. Children with developmental dyslexia showed similar congruency effects for letters and non-letters, thus differing even from reading-level matched controls. Note, however, that the locus of the congruency effect found for letters and for non-letters by children with developmental dyslexia differed: whereas the non-letter congruency effect was predicted by visuospatial abilities, the letter congruency effect depended on phonological recoding. This pattern of results suggests that children with developmental dyslexia do have a deficit in letter processing, whose locus is phonological. Regarding our research question, this pattern of results suggests that developmental dyslexia and functional illiteracy do not share deficits in single letter processing.

Due to the methodological heterogeneity of these studies (see Tables 3, 4), a meta-analysis of the available data was not possible. Therefore, in the following sections, a qualitative synthesis is provided concerning two parameters: (a) definitions, terminology and criteria for inclusion, and (b) research focus and outcome measures.

\section{Definitions, terminology and criteria for inclusion}

The definitions and terminologies of functional illiteracy and criteria for inclusion in a sample are not consistent between studies. Regarding definition and terminology, all the considered articles used different terms for the group, defined here as functional illiterate individuals (see Tables 3, 4). For samples including adults who attended education in childhood, the terms functional illiterate adults (Rüsseler et al. 2011), semi-literate readers (Flint and Pammer 2018) and adult poor readers (Mahé et al. 2013) were used. 
For those functional illiterate individuals who acquired literacy skills outside regular schooling in adulthood, who had no access to education in childhood, the terms low literacy adults (Jiménez's et al. 2010) and ex-illiterates (Fernandes et al. 2014) were used.

Regarding the inclusion of the participants, Rüsseler et al. (2011) and Mahé et al. (2013) did not report strict ad hoc criteria, but both matched their samples based either on age and/or IQ, or on reading level, respectively. Besides these matching variables, Jiménez et al. (2010) and Fernandes et al. (2014) additionally used proficiency levels for adult literacy courses, not described in detail. In Jiménez et al. (2010), the functional illiterate individuals failed to achieve a certificate for the successful completion of an adult literacy course, while in Fernandes et al. (2014) the completion of the 4th level of literacy was used as inclusion criterion. Instead of applying matching variables, Flint and Pammer (2018) included adults who could read simple sentences but could not decode complex words or sentences in the functional illiterate group. Note, however, that these participants in this study attended school in childhood in Papua New Guinea. There, the average years of schooling (2010: 4.26 years, Barro and Lee 2013) and the literacy rate (2010: 61.6\%, UNESCO Institute for Statistics 2019) are both considerably lower than in the countries in which the other studies recruited their participants.

The definitions, terminologies, and inclusion criteria adopted for developmental dyslexia are more consistent across studies than those for functional illiteracy. Four articles were consistent in adopting the term dyslexia or developmental dyslexia. These relied on a diagnosis either in childhood (Fernandes et al. 2014; Mahé et al. 2013; Rüsseler et al. 2011) or in adulthood (Flint and Pammer 2018). Only one study (Jiménez et al. 2010) applied the term reading disabled children, which was defined as those who reached a Percentile score lower than 25 on a pseudoword reading task and performed at the level of Grade 2 on a word reading test.

Even though we identified consistency between the studies regarding developmental dyslexia, we found great heterogeneity with respect to the groups with functional illiteracy, which makes it hard to systematically compare the results of the studies.

\section{Research focus and outcome measures}

The studies either focused on a possible shared causal deficit at the biological level between the groups (Flint and Pammer 2018; Mahé et al. 2013), or they examined information processing, either low level perception (Rüsseler et al. 2011) or cognitive performance in the groups (Fernandes et al. 2014; Jiménez et al. 2010). The outcomes from different perceptual and cognitive skills were measured in the studies by using different methods. In two of the studies (Jiménez et al. 2010; Rüsseler et al. 2011) the outcome measures relevant for the research questions come from standardized tests, while for the other three studies (Fernandes et al. 2014; Flint and Pammer 2018; Mahé et al. 2013) experiments were designed and applied. Rüsseler et al. (2011) applied a large variety of lowlevel perceptual tasks, such as visual and auditory temporal order judgment, auditory direction judgment, auditory discrimination (pitch, duration and frequency) and auditory-motor coordination. Three studies used verbal stimuli: Fernandes et al. (2014) in a same-different matching task with letters and pseudoletters, Mahé et al. (2013) in a lexical decision task with word-like and non-verbal stimuli and Jiménez et al. (2010) in isolation, segmentation, deletion and blending tasks. Flint and Pammer (2018) used visual motion and form detection, and binary search tasks.

Results of the quality evaluation

In order to evaluate the quality of methods and of reporting, we followed the recommendation by Sirriyeh et al. (2012) for quantitative studies, to use 14 out of the total of 16 items of the QATSDD. Some items had to be adapted to the typical design of the selected studies, such as the item about relevance of recruitment information (lab studies vs. data collection in Papua New Guinea, or about the reliability and validity of the tools and user involvement: normed tests vs. experimental tasks).

The evaluation of the five studies resulted in scores between 59.5 and $76.2 \%$ (Table 5). In our view, a meaningful comparison of the studies based on their evaluation score is problematic, because the quality of reporting depends substantially on the scientific field and on the journal in which the article was published (e.g., journals with limited length). Thus, if the authors' argumentation was revealed to be not detailed 
Table 5 Results of the quality assessment and agreement between the coders

\begin{tabular}{lllc}
\hline & QATSDD overall score (\%) & \multicolumn{2}{l}{ Agreement between the coders } \\
\cline { 3 - 4 } & & Percent agreement & Weighted $\kappa$ \\
\hline Rüsseler et al. (2011) & 64.23 & 78.57 & 0.835 \\
Flint and Pammer (2018) & 71.43 & 71.43 & 0.745 \\
Mahé et al. (2013) & 59.52 & 78.57 & 0.783 \\
Jiménez et al. (2010) & 76.19 & 64.29 & 0.622 \\
Fernandes et al. (2014) & 69.05 & 64.29 & 0.608 \\
\hline
\end{tabular}

enough according to the QATSDD scale, it could still be appropriate and well received as typical in the field. For instance, in psychology, it is not common to give detailed descriptions of standardized tests, since these are well known in the community and when published are cited and hence detailed information is available elsewhere. However, according to the QATSDD scale, this information is expected. Moreover, although all five studies are dealing with quantitative data, they varied greatly concerning their research questions, applied methods, and outcome measures. These differences do not allow a meaningful comparison between the QATSDD scores.

\section{Discussion}

The present systematic review aimed at identifying and summarizing the available evidence investigating the possible connection and overlap between functional illiteracy and developmental dyslexia. The search strategy and eligibility criteria were chosen based on the assumption that only a limited number of outcomes would result. Therefore, we used a more sensitive search strategy, i.e., a broad question, a large number of search terms in two languages, only few and more liberal criteria (no restrictions on, e.g., study designs, outcome measures, publication year, or study quality), in order to decrease the risk of missing records. The search strategy was developed and eligibility criteria were chosen in close collaboration with a group of four international experts from the field (see: "Acknowledgements").

The comprehensive search resulted in only five eligible studies, indicating that scientific work on systematically investigating the similarities between functional illiteracy and developmental dyslexia is rare. Moreover, the identified studies were conducted in different countries with different orthographic systems, they used different definitions and terminology for the group we termed here as functional illiterates, and they used different criteria for inclusion of individuals to this group.

Similarities and differences between functional illiteracy and developmental dyslexia

Given the heterogeneity across studies in respect to the group of functional illiterate individuals, conclusions about similarities and differences between functional illiterate individuals and people with developmental dyslexia must be drawn with caution. On the one hand, the comparison in low level perception revealed similarities between the functional illiterate and developmental dyslexic groups, while both performed worse than skilled readers (Rüsseler et al. 2011). This pattern was also found for phonological awareness skills (Jiménez et al. 2010). Although the overall performance of the two groups of our interest was comparable and only differed in phoneme deletion (functional illiterate individuals achieved lower), both groups were characterized by low phonological awareness and possible phonological impairments. Please note, however, when referring to similarities between the groups in the case of Rüsseler et al. (2011) and Jiménez et al. (2010), these similarities indicate that the studies failed to find differences between their difficulties (see effect size calculations in Supplementary Tables 1-6). Although the groups with functional illiterate and dyslexic individuals performed significantly weaker than the skilled reading control groups, in order to find out whether their difficulties are indeed the same, stronger statistical analyses are needed. Whether non-significant differences reflect similarity, rather than low statistical power or sampling error cannot be firmly defined (see, e.g., Dienes 2014). 
On the other hand, the other three articles (Fernandes et al. 2014; Flint and Pammer 2018; Mahé et al. 2013), instead of similarities, found significant differences between functional illiterate individuals and participants with developmental dyslexia. Both experiments by Flint and Pammer (2018) brought the same conclusion, i.e., a magno/dorsal impairment was specifically found in people with developmental dyslexia, which was a likely cause of their reading disorder, whereas no deficit was found in functional illiterate individuals. Mahé et al. (2013) revealed that functional illiterate participants perform better at the behavioral level compared to adults with developmental dyslexia. Moreover, at the biological level, functional illiterate individuals' N170 print tuning was more similar to skilled readers than to individuals with developmental dyslexia. This suggests that impaired N170 specialization is a hallmark of developmental dyslexia, but not functional illiteracy. In the same vein, Fernandes et al. (2014) found that functional illiterate individuals generally performed faster and more accurate in their recognition task than children with developmental dyslexia did. They also showed a similar processing distinction between letters and nonletters as skilled readers did, whereas children with developmental dyslexia did not.

Taken together, the results of two studies suggest that individuals with functional illiteracy and with developmental dyslexia may share certain commonalities in low level auditory and visual perception (Rüsseler et al. 2011) and phonological awareness, or at least on some component of metaphonological processing (Jiménez et al. 2010). However, regarding several perceptual and cognitive functions, especially those related to reading and orthographic processing, functional illiterate adults do differ from individuals with developmental dyslexia, more closely resembling typical readers.

\section{Conclusions and perspectives}

The current review could not fully answer how many commonalities are shared between functional illiterate individuals and people with developmental dyslexia. However, the present work is a first step in the systematic comparison of studies between these groups. From the scarce research available which has directly compared these two groups, it is clear that there are not only commonalities, but there are also substantial differences between them, especially regarding reading-relevant basic information processing (e.g., Fernandes et al. 2014; Mahé et al. 2013). Although, on the surface, the groups seems to have some similarities in their cognitive profile, it does not mean that the mechanisms underlying their difficulties are actually comparable (see also the discussion about the similarities and differences between developmental and acquired dyslexia; Snowling et al. 1996). Nonetheless, there are similarities in the two populations, they both seem to have comparable deficits in phonological awareness (Jiménez et al. 2010) and low level auditory and visual perception skills in computerized tests (Rüsseler et al. 2011). From these results, two aspects must be considered. First, given the major impact of learning to read in other cognitive skills (for a review, see, Dehaene et al. 2015), it could be the case that instead of a common locus, these deficits were rather a reflection of the consequence that low reading skills would have on other cognitive domains (for a discussion, see, e.g., Huettig et al. 2018). Second, these similarities hold some promise on intervention programs with functional illiterate individuals. For children with developmental dyslexia, phonics-based interventions including auditory-phonological training have been shown to be effective in fostering literacy skills (see Ehri et al. 2001; McArthur et al. 2018, for reviews, see also Suggate 2016), which could also hold true for functional illiterate adults. If it would, according to the Response to Intervention approach, this would provide support for a shared cause or shared consequences of low reading skills. Regarding the training of isolated, basic, non-linguistic auditory and visual processing, some studies found transfer effects to literacy skills in dyslexic children (e.g., Kujala et al. 2001), whereas the majority of more recent studies report no transfer (Ise et al. 2012; Koether et al. 2008). Regarding intervention, generally a training of isolated perceptual or cognitive functions is not likely to led to a transfer (e.g., Galuschka and Schulte-Körne 2016). However, including a training of basic perceptual functions in a modularized, complex literacy training for adults, that also includes phonics-based reading and writing instruction has been shown to be effective (Rüsseler et al. 2013).

Systematically collecting and summarizing the available studies that include both functional illiterate 
and developmental dyslexic groups could not answer our straightforward research question satisfactorily. There are not enough studies assessing both groups simultaneously and the existing ones are rather heterogeneous in many respects, making a systematic comparison impossible. This gap needs to be closed by further and well-designed empirical studies. The following recommendations could be made to improve the quality and the comparability of these future studies. In order to avoid mixing functional illiteracy with other poor reading groups (e.g., who had no access to school in childhood, who are second language learners), studies should offer clear definitions of functional illiteracy and report what criteria they used for sample inclusion. The description of the sample should include, for instance, the level of formal schooling, the socioeconomic background, the reading level (expressed in grade equivalent score by a normed assessment measuring reading accuracy, speed or comprehension), language acquisition (spoken language in childhood, migration background) and previously diagnosed learning disabilities (including the assessment of family history). In order to learn more about the commonalities and differences between functional illiteracy and developmental dyslexia, studies also need to match participants in reading level and age with the control groups to differentiate between cause and effect. As long as such studies comparing both groups are not available, a promising approach would be to systematically collect and summarize studies examining the functional illiterate group and then comparing the results narratively with studies testing the same functions in the developmental dyslexia group (see Lachmann et al. 2020a).

Acknowledgements This project was supported by the German Federal Ministry of Educational Research (BMBF 01GJ1801). Thanks are due to the members of the scientific advisory board of this project, for their valuable contributions: Régine Kolinsky (Université Libre de Bruxelles, Belgium), Mary-Helen Kosmidis (Aristotle University of Thessaloniki, Greece), Claudia Mähler (University of Hildesheim, Germany), and Sven Nickel (University of Bremen, Germany).

Author contributions All authors contributed to the design and implementation of the research. The screening and evaluation procedure was implemented by $\mathrm{RV}, \mathrm{KB}, \mathrm{AB}, \mathrm{MK}$, and TL. The manuscript was written by the first (RV) and the senior (TL) author with support of $\mathrm{KB}, \mathrm{AB}, \mathrm{MK}$. All others authors contributed significantly.
Funding Open Access funding enabled and organized by Projekt DEAL. This project was supported by the German Federal Ministry of Educational Research (BMBF 01GJ1801).

Availability of data and material Archiving is not mandated but data will be made available on reasonable request.

Code availability Not applicable.

\section{Compliance with ethical standards}

Conflict of interest On behalf of all authors, the corresponding author states that there is no conflict of interest.

Ethics approval Not applicable.

Open Access This article is licensed under a Creative Commons Attribution 4.0 International License, which permits use, sharing, adaptation, distribution and reproduction in any medium or format, as long as you give appropriate credit to the original author(s) and the source, provide a link to the Creative Commons licence, and indicate if changes were made. The images or other third party material in this article are included in the article's Creative Commons licence, unless indicated otherwise in a credit line to the material. If material is not included in the article's Creative Commons licence and your intended use is not permitted by statutory regulation or exceeds the permitted use, you will need to obtain permission directly from the copyright holder. To view a copy of this licence, visit http://creativecommons.org/licenses/by/4.0/.

\section{References}

Ardila, A., Bertolucci, P. H., Braga, L. W., Castro-Caldas, A., Judd, T., Kosmidis, M. H., et al. (2010). Illiteracy: The neuropsychology of cognition without reading. Archives of Clinical Neuropsychology, 25(8), 689-712. https://doi.org/ 10.1093/arclin/acq079.

Bar-Kochva, I., Vágvölgyi, R., \& Bulajić, A. (2019). The abilities and deficits in reading and writing of low literate adults. In M. Schemmann (Ed.), Internationales Jahrbuch der Erwachsenenbildung/International yearbook of adult education (pp. 81-100). Bielefeld: wbv.

Barnes, A. E., Kim, Y. S., Tighe, E. L., \& Vorstius, C. (2017). Readers in adult basic education: Component skills, eye movements, and fluency. Journal of Learning Disabilities, 50(2), 180-194. https://doi.org/10.1177/0022219415 609187.

Barro, R. J., \& Lee, J. W. (2013). A new data set of educational attainment in the world, 1950-2010. Journal of Development Economics, 104, 184-198. https://doi.org/10.1016/j. jdeveco.2012.10.001.

Becker, C., Elliott, M. A., \& Lachmann, T. (2005). Evidence for impaired visuoperceptual organisation in developmental dyslexics and its relation to temporal processes. Cognitive Neuropsychology, 22(22231608), 499-522. https://doi.org/ $10.1080 / 02643290442000086$. 
Binder, K. S., Chace, K. H., \& Manning, M. C. (2007). Sentential and discourse context effects: Adults who are learning to read compared with skilled readers. Journal of Research in Reading, 30(4), 360-378. https://doi.org/10. 1111/j.1467-9817.2007.00349.x.

Boltzmann, M. (2014). Schriftsprachverarbeitung funktionaler Analphabeten in Deutschland. Mönchengladbach: Verlag für Kognitive Neurowissenschaften.

Boltzmann, M., Mohammadi, B., Samii, A., Münte, T. F., \& Rüsseler, J. (2017). Structural changes in functionally illiterate adults after intensive training. Neuroscience, 344, 229-242. https://doi.org/10.1016/j.neuroscience.2016.12. 049.

Boltzmann, M., \& Rüsseler, J. (2013). Training-related changes in early visual processing of functionally illiterate adults: Evidence from event-related brain potentials. $\mathrm{BMC} \mathrm{Neu-}$ roscience, 14, 154. https://doi.org/10.1186/1471-2202-14154.

Bulajić, A., Despotović, M., \& Lachmann, T. (2019). Understanding functional illiteracy from a policy, adult education, and cognition point of view: Towards a joint referent framework. Zeitschrift Für Neuropsychologie, 30(2), 109-122.

Christmann, C. A., Lachmann, T., \& Steinbrink, C. (2015). Evidence for a general auditory processing deficit in developmental dyslexia from a discrimination paradigm using speech versus nonspeech sounds matched in complexity. Journal of Speech Language and Hearing Research, 58, 107-121. https://doi.org/10.1044/2014.

Coltheart, M. (2005). Modeling reading: The dual-route approach. In M. J. Snowling \& C. Hulme (Eds.), The science of reading: A handbook (pp. 6-23). Hoboken: Blackwell Publishing Ltd.

Council, E. (2018). Council recommendation of 22 May 2018 on key competences for lifelong learning. Official Journal of the European Union, 61(C 189).

Cree, A., Kay, A., \& Steward, J. (2012). The economic and social cost of illiteracy: A snapshot of illiteracy in a global context. Melbourne: The World Literacy Foundation.

CTB/McGraw-Hill. (2008). Discover TABE 9\&10. Discover. Monterey: CTB/McGraw-Hill.

Dehaene, S., Cohen, L., Morais, J., \& Kolinsky, R. (2015). Illiterate to literate: Behavioural and cerebral changes induced by reading acquisition. Nature Reviews Neuroscience, 16(4), 234-244. https://doi.org/10.1038/nrn3924.

Dehaene, S., Pegado, F., Braga, L. W., Ventura, P., Nunes Filho, G., Jobert, A., et al. (2010). How learning to read changes the cortical networks for vision and language. Science (New York, NY), 330(6009), 1359-1364. https://doi.org/10. 1126/science.1194140.

Dienes, Z. (2014). Using Bayes to get the most out of nonsignificant results. Frontiers in Psychology. https://doi.org/ 10.3389/fpsyg.2014.00781.

Döbert, M., \& Hubertus, P. (2000). Ihr Kreuz ist die Schrift. Analphabetismus und Alphabetisierung in Deutschland. Retrieved from http://digitool.hbz-nrw.de:1801/webclient/ DeliveryManager?pid=2924879.

Ehri, L. C., Nunes, S. R., \& Stahl, S. A. (2001). Systematic phonics instruction helps students learn to read: Evidence from the National Reading Panel's meta-analysis. Review of Educational Research, 71(3), 393-447.
Eme, E., Lacroix, A., \& Almecija, Y. (2010). Oral narrative skills in french adults who are functionally illiterate: Linguistic features and discourse organization. Journal of Speech Language and Hearing Research, 53(5), 1349. https://doi.org/10.1044/1092-4388(2010/08-0092).

Eme, E., Lambert, E., \& Alamargot, D. (2014). Word reading and word spelling in French adult literacy students: The relationship with oral language skills. Journal of Research in Reading, 37(3), 268-296. https://doi.org/10.1111/j. 1467-9817.2011.01508.x.

Farmer, M. E., \& Klein, R. M. (1995). The evidence for a temporal processing deficit linked to dyslexia: A review. Psychonomic Bulletin and Review, 2(4), 460-493. https:// doi.org/10.3758/BF03210983.

Fernandes, T., Vale, A. P., Martins, B., Morais, J., \& Kolinsky, R. (2014). The deficit of letter processing in developmental dyslexia: Combining evidence from dyslexics, typical readers and illiterate adults. Developmental Science, 17(1), 125-141. https://doi.org/10.1111/desc.12102.

Flint, S., \& Pammer, K. (2018). It is the egg, not the chicken; dorsal visual deficits present in dyslexia are not present in illiterate adults. Dyslexia, 25(1), 69-83. https://doi.org/10. 1002/dys. 1607.

Frith, U. (1986). A developmental framework for developmental dyslexia. Annals of Dyslexia, 36(1), 67-81.

Galuschka, K., \& Schulte-Körne, G. (2016). Clinical practice guideline: The diagnosis and treatment of reading and/or spelling disorders in children and adolescents. Dtsch Arztebl Int, 113, 279-286.

Gottesman, R. L., Bennett, R. E., Nathan, R. G., \& Kelly, M. S. (1996). Inner-city adults with severe reading difficulties: A closer look. Journal of Learning Disabilities, 29(6), 589-597.

Greenberg, D., Ehri, L. C., \& Perin, D. (1997). Are word-reading processes the same or different in adult literacy students and third-fifth graders matched for reading level? Journal of Educational Psychology, 89(2), 262-275. https://doi. org/10.1037/0022-0663.89.2.262.

Greenberg, D., Ehri, L. C., \& Perin, D. (2002). Do adult literacy students make the same word-reading and spelling errors as children matched for word-reading age? Scientific Studies of Reading, 6(3), 221-243.

Grosche, M. (2012). Analphabetismus und Lese-RechtschreibSchwächen. Münster: Waxmann.

Grosche, M., \& Grünke, M. (2011). Beeinträchtigungen in der phonologischen Informationsverarbeitung bei funktionalen Analphabeten. Zeitschrift Fur Padagogische Psychologie, 25(4), 277-291. https://doi.org/10.1024/ 1010-0652/a000051.

Groth, K., Lachmann, T., Riecker, A., Muthmann, I., \& Steinbrink, C. (2011). Developmental dyslexics show deficits in the processing of temporal auditory information in German vowel length discrimination. Reading and Writing, 24(3), 285-303. https://doi.org/10.1007/s11145-009-9213-7.

Grotlüschen, A., Buddeberg, K., Dutz, G., Heilmann, L., \& Stammer, C. (2019). LEO 2018-living with low literacy. Hamburg: Press brochure.

Grotlüschen, A., Buddeberg, K., Dutz, G., Heilmann, L., \& Stammer, C. (2020). Hauptergebnisse und Einordnung tur LEO-Studie 2018-Leben mit geringer Literalität. In A. 
Grotlüschen \& K. Buddeberg (Eds.), Leo 2018. Leben mit geringer Literalität (pp. 13-64). Bielefeld: wbv.

Grotlüschen, A., \& Riekmann, W. (2011). leo-Level one study. Hamburg: Universität Hamburg.

Heilmann, L. (2020). Literalität, gezundheitsbezogene Praktiken und Grundkompetenzen. In A. Grotlütschen \& K. Buddeberg (Eds.), LEO 2018. Leben mit geringer Literalität (pp. 255-286). Bielefeld: wbv.

Heim, S., Tschierse, J., Amunts, K., Wilms, M., Vossel, S., Willmes, K., et al. (2008). Cognitive subtypes of dyslexia. Acta Neurobiologiae Experimentalis, 68(1), 73-82.

Hemmerechts, K., Agirdag, O., \& Kavadias, D. (2016). The relationship between parental literacy involvement, socioeconomic status and reading literacy. Educational Review, 69(1), 85-101. https://doi.org/10.1080/00131911.2016. 1164667.

Huettig, F., Lachmann, T., Reis, A., \& Petersson, K. M. (2018). Distinguishing cause from effect-Many deficits associated with developmental dyslexia may be a consequence of reduced and suboptimal reading experience. Language Cognition and Neuroscience, 33(3), 333-350. https://doi. org/10.1080/23273798.2017.1348528.

Huettig, F., \& Mishra, R. K. (2014). How literacy acquisition affects the illiterate mind-A critical examination of theories and evidence. Linguistics and Language Compass, 8(10), 401-427. https://doi.org/10.1111/lnc3.12092.

Hulme, C., \& Snowling, M. J. (2009). Developmental disorders of language learning and cognition. New York: Wiley.

Ise, E., Engel, R. R., \& Schulte-Körne, G. (2012). Was hilft bei der Lese-Rechtschreibstörung? Ergebnisse einer Metaanalyse zur Wirksamkeit deutschsprachiger Förderansätze. Kindheit Und Entwicklung, 21(2), 122-136. https://doi. org/10.1026/0942-5403/a000077.

Jeantheau, J.-P. (2015). IVQ 2011. What lessons can be drawn from the evolution of the state of adult literacy in France? In A. Grotlüschen \& D. Zimper (Eds.), Literalitäts- und Grundlagenforschung. Alphabetisierung und Grundbildung (Vol. 11, pp. 177-196). Münster: Waxmann Verlag.

Jiménez, J. E. (1995). Evaluación de la conciencia fonológica [Assessment of phonological awareness]. In J. E. Jiménez \& M. R. Ortiz (Eds.), Conciencia fonológica y aprendizaje de la lectura (Phonological awareness and learning to read) (pp. 74-78). Madrid: Síntesis.

Jiménez, J. E., García, E., \& Venegas, E. (2010). Are phonological processes the same or different in low literacy adults and children with or without reading disabilities? Reading and Writing, 23(1), 1-18. https://doi.org/10.1007/ s11145-008-9146-6.

Klatte, M., Steinbrink, C., Bergström, K., \& Lachmann, T. (2013). Phonologische Verarbeitung bei Grundschulkindern mit schwacher Lesefähigkeit. Lernen Und Lernstörungen, 2(4), 199-215.

Koether, R., Schumacher, B., Scheller, K., van Leeuwen, C., \& Lachmann, T. (2008). The relation between speed of visual-auditory integration and General Intelligence in dyslexics and normal reading children. In Proceedings of the 23rd annual meeting of the ISP (pp. 357-362). https:// doi.org/10.1017/CBO9781107415324.004.

Kujala, T., Karma, K., Ceponiene, R., Belitz, S., Turkkila, P., Tervaniemi, M., \& Näätänen, R. (2001). Plastic neural changes and reading improvement caused by audiovisual training in reading-impaired children. PNAS, 98(18), 10509-10514.

Lachmann, T. (2002). Reading disability as a deficit in functional coordination and information integration. In $\mathrm{E}$. Witruk, A. D. Friederici, \& T. Lachmann (Eds.), Basic functions of language, reading and reading disability (pp. 165-198). Boston: Kluwer Academic Publishers.

Lachmann, T. (2018). Reading and dyselxia: The functional coordination framework. In T. Lachmann \& T. Weis (Eds.), Reading and dyslexia: From basic functions to higher order cognition (pp. 265-290). Cham: Springer International Publishing AG.

Lachmann, T., Berti, S., Kujala, T., \& Schröger, E. (2005). Diagnostic subgroups of developmental dyslexia have different deficits in neural processing of tones and phonemes. International Journal of Psychophysiology, 56(2), 105-120. https://doi.org/10.1016/j.ijpsycho.2004.11.005.

Lachmann, T., Khera, G., Srinivasan, N., \& van Leeuwen, C. (2012). Learning to read aligns visual analytical skills with grapheme-phoneme mapping: Evidence from illiterates. Frontiers in Evolutionary Neuroscience, 4, 1-8. https://doi. org/10.3389/fnevo.2012.00008.

Lachmann, T., Vágvölgyi, R., Bergström, K., Bulajić, A., \& Klatte, M. (2020a). A systematic review on functional illiteracy: Risk factors, cognitive profiles, prevention, and intervention. International Prospective Register of Systematic Reviews. PROSPERO 2020, (CRD42020179537). Retrieved from https://www.crd.york.ac.uk/prospero/ display_record.php?ID=CRD42020179537.

Lachmann, T., Vágvölgyi, R., Bergström, K., Bulajić, A., \& Klatte, M. (2020b). The similarities and differences between functional illiteracy and developmental dyslexia: A systematic review. International Prospective Register of Systematic Reviews. PROSPERO 2020, (CRD4202015 6766). Retrieved from https://www.crd.york.ac.uk/ prospero/display_record.php?ID=CRD42020156766.

Lachmann, T., \& van Leeuwen, C. (2008a). Different letterprocessing strategies in diagnostic subgroups of developmental dyslexia. Cognitive Neuropsychology, 25(5), 730-744. https://doi.org/10.1080/02643290802309514.

Lachmann, T., \& van Leeuwen, C. (2008b). Differentiation of holistic processing in the time course of letter recognition. Acta Psychologica, 129(1), 121-129. https://doi.org/10. 1016/j.actpsy.2008.05.003.

Landgraf, S., Beyer, R., Hild, I., Schneider, N., Horn, E., Schaadt, G., et al. (2012). Impact of phonological processing skills on written language acquisition in illiterate adults. Developmental Cognitive Neuroscience, 2(SUPPL. 1), S129-S138. https://doi.org/10.1016/j.den.2011.11.006.

Livingstone, M. S., Rosen, G. D., Drislane, F. W., \& Galaburda, A. M. (1991). Physiological and anatomical evidence for a magnocellular defect in developmental dyslexia. Proceedings of the National Academy of Sciences of the United States of America, 88(18), 7943-7947. https://doi.org/10. 1073/pnas.88.18.7943.

Lovegrove, W., Martin, F., \& Slashuis, W. (1986). A theoretical and experimental case for a visual deficit in specific reading disability. Cognitive Neuropsychology, 3(2), 225-267. https://doi.org/10.1080/02643298608252677.

MacArthur, C. A., Konold, T. R., Glutting, J. J., \& Alamprese, J. A. (2010). Reading component skills of learners in adult 
basic education. Journal of Learning Disabilities, 43(2), 108-121. https://doi.org/10.1177/0022219409359342.

MacArthur, C., Konold, T. R., Glutting, J. J., \& Alamprese, J. A. (2012). Subgroups of adult basic education learners with different profiles of reading skills. Reading and Writing, 25(2), 587-609. https://doi.org/10.1038/jid.2014.371.

Mahé, G., Bonnefond, A., \& Doignon-Camus, N. (2013). Is the impaired N170 print tuning specific to developmental dyslexia? A matched reading-level study with poor readers and dyslexics. Brain and Language, 127(3), 539-544. https://doi.org/10.1016/j.bandl.2013.09.012.

Mahé, G., Bonnefond, A., Gavens, N., Dufour, A., \& DoignonCamus, N. (2012). Impaired visual expertise for print in French adults with dyslexia as shown by N170 tuning. Neuropsychologia, 50(14), 3200-3206. https://doi.org/10. 1016/j.neuropsychologia.2012.10.013.

Maurer, U., Brem, S., Bucher, K., \& Brandeis, D. (2005). Emerging neurophysiological specialization for letter strings. Journal of Cognitive Neuroscience, 17(10), 1532-1552. https://doi.org/10.1162/089892905774597218.

Maurer, U., \& McCandliss, B. D. (2007). The development of visual expertise for words: The contribution of electrophysiology. In E. L. Grigorenko, \& A. Naples (Eds.), Single-Word Reading: Behavioral and Biological Perspectives (pp. 43-63). https://doi.org/https://doi.org/10. 4324/9780203810064.

McArthur, G., Sheehan, Y., Na, B., Da, F., Hc, W., Kohnen, S., et al. (2018). Phonics training for English-speaking poor readers. Cochrane Database of Systematic Reviews. https:// doi.org/10.1002/14651858.CD009115.pub3.www. cochranelibrary.com.

Mellard, D. F., \& Patterson, M. B. (2008). Contrasting adult literacy learners with and without specific learning disabilities. Remedial and Special Education, 29, 133-144. https://doi.org/10.1177/0741932508315053.

Moher, D., Liberati, A., Tetzlaff, J., Altman, D. G., \& The PRISMA Group. (2009). Preferred reporting items for systematic reviews and meta-analyses: The PRISMA statement. PLoS Med, 6(7), 889-896. https://doi.org/10. 1371/journal.pmed.1000097.

Nickel, S. (2007). Family-orientated basic education in the social space as a key-strategy for extended participation in literacy. In A. Grotlüschen \& A. Linde (Eds.), Literalität, Grundbildung oder Lesekompetenz? Beiträge zu einer TheoriePraxis-Diskussion (pp. 182-192). Münster: Waxmann.

Nicolson, R. I., \& Fawcett, A. J. (1990). Automaticity: A new framework for dyslexia research? Cognition, 35, 159-182. https://doi.org/10.1080/00223131.2002.10875205.

Nicolson, R. I., \& Fawcett, A. (2018). Procedural learning, dyslexia and delayed neural commitment. In T. Lachmann \& T. Weis (Eds.), Reading and dyslexia: From basic functions to higher order cognition (pp. 229-264). Berlin: Springer International Publishing AG.

OECD (2013). OECD Skills Outlook 2013: First Results from the Survey of Adult Skills. OECD Publishing. https://doi. org/10.1787/9789264204256-en.

OECD (2019). Skills Matter: Additional Results from the Survey of Adult Skills. OECD Publishing. https://doi.org/10.1787/ be1a9160-en.

Pugh, K. R., Mencl, W. E., Jenner, A. R., Katz, L., Frost, S. J., Lee, J. R., et al. (2000). Functional neuroimaging studies of reading and reading disability (developmental dyslexia). Mental Retardation and Developmental Disabilities Research Reviews, 6(3), 207-213. https://doi.org/10.1002/ 1098-2779(2000)6:3\%3c207::AID-MRDD8\%3e3.0.CO;2-P.

Ramus, F., Rosen, S., Dakin, S. C., Day, B. L., Castellote, J. M., White, S., \& Frith, U. (2003). Theories of developmental dyslexia: Insights from a multiple case study of dyslexic adults. Brain, 126(4), 841-865. https://doi.org/10.1093/ brain/awg076.

Rüsseler, J., Boltzmann, M., Menkhaus, K., \& Aulbert-Siepelmeyer, A. (2013). Evaluation eines neuen Trainingsprogramms zur Verbesserung der Lese- und Rechtschreibfähigkeiten funktionaler Analphabeten. Empirische Sonderpädagogik, 3, 237-249.

Rüsseler, J., Gerth, I., \& Boltzmann, M. (2011). Basale Wahrnehmungsfähigkeiten von erwachsenen funktionalen Analphabeten und Analphabetinnen. In Projektträger im DLR (Ed.), Lernprozesse in Alphabetisierung und Grundbildung Erwachsener. Diagnostik, Vermittlung, Professionalisierung (pp. 11-28). Bielefeld: WBV-Verlag.

Rüsseler, J., Menkhaus, K., Aulbert-Siepelmeyer, A., Gerth, I., \& Boltzmann, M. (2012). "Alpha Plus": An innovative training program for reading and writing education of functionally illiterate adults. Creative Education, 03(3), 357-361. https://doi.org/10.4236/ce.2012.33056.

Share, D. (1995). Phonological recoding and selfteaching: Sine qua non of reading acquisition. Cognition, 55, 151-218.

Sirriyeh, R., Lawton, R., Gardner, P., \& Armitage, G. (2012). Reviewing studies with diverse designs: The development and evaluation of a new tool. Journal of Evaluation in Clinical Practice, 18(4), 746-752. https://doi.org/10.1111/ j.1365-2753.2011.01662.x.

Snowling, M. J. (2001). From language to reading and dyslexia. Dyslexia, 7(1), 37-46. https://doi.org/10.1002/dys.185.

Snowling, M. J., Bryant, P. E., \& Hulme, C. (1996). Theoretical and methodological pitfalls in making comparisons between developmental and acquired dyslexia: Some comments on A. Castles and M. Coltheart (1993). Reading and Writing, 8(5), 443-451. https://doi.org/10.1007/ BF00404005.

Stein, J. (2018). The magnocellular theory of developmental dyslexia. In T. Lachmann \& T. Weis (Eds.), Reading and dyslexia: From basic functions to higher order cognition (pp. 103-134). Berlin: Springer International Publishing AG.

Stein, J. F. (2018). Does dyslexia exist? Language Cognition and Neuroscience, 33(3), 313-320. https://doi.org/10. 1080/23273798.2017.1325509.

Steinbrink, C., Groth, K., Lachmann, T., \& Riecker, A. (2012). Neural correlates of temporal auditory processing in developmental dyslexia during German vowel length discrimination: An fMRI study. Brain and Language, 121(1), 1-11. https://doi.org/10.1016/j.bandl.2011.12.003.

Steinbrink, C., Klatte, M., \& Lachmann, T. (2014). Phonological, temporal and spectral processing in vowel length discrimination is impaired in German primary school children with developmental dyslexia. Research in Developmental Disabilities, 35(11), 3034-3045. https://doi.org/10.1016/j. ridd.2014.07.049.

Sucena, A., \& Castro, S. L. (2008). Aprender a ler e Avaliar a Leitura [Learning how to read and the assessment of reading]. Coimbra: Almedina. 
Suggate, S. P. (2016). A meta-analysis of the long-term effects of phonemic awareness, phonics, fluency, and reading comprehension interventions. Journal of Learning Disabilities, 49(1), 77-96. https://doi.org/10.1177/002221941 4528540.

Swanson, H. L., \& Hsieh, C.-J. (2009). Reading disabilities in adults: A selective meta-analysis of the literature. Review of Educational Research, 79(4), 1362-1390.

Tal, N. F., Siegel, L. S., \& Maraun, M. (1994). The role of question type and reading ability in reading comprehension. Reading and Writing, 6(4), 387-402.

Tallal, P. (1980). Auditory temporal perception, phonics, and reading disabilities in children. Brain and Language, 9(2), 182-198. https://doi.org/10.1016/0093-934X(80) 90139-X.

Tewes, U., \& Steffen, S. (2003). Automatisierungsstörungen als Ursache von Lernproblemen Automatisierungsstörungen als Ursache von Lernproblemen. InForum Logopädie, 2003(1), 1-8.

Thompkins, A. C., \& Binder, K. S. (2003). A comparison of the factors affecting reading performance of functional illiterate adults and children matched by reading level. Reading Research Quarterly, 38, 236-258.

UNESCO. (1979). Records of the General Conference. 20th session (Vol. 1). Paris: UNESCO.

UNESCO (2006). Why literacy matters. In UNESCO (Ed.), Education for all. Literacy for life (pp. 135-145). Paris: UNESCO.

UNESCO Institute for Statistics. (2019). Data Centre. Retrieved November 20, 2020, from http://data.uis.unesco.org/.

US Department of Education. (2016). Implementation guidelines: Measures and methods for the national reporting system for adult education. Fundamentals of EMS, NMS and OSS/BSS. https://doi.org/10.1201/b15748-30.
Vágvölgyi, R. (2018). Linguistic, numerical and cognitive foundations of functional illiteracy. Tübingen: EberhardKarls-Universität Tübingen.

Vágvölgyi, R., Coldea, A., Dresler, T., Schrader, J., \& Nuerk, H.-C. (2016). A review about functional illiteracy: Definition, cognitive, linguistic, and numerical aspects. Frontiers in Psychology, 7, 17-29. https://doi.org/10.3389/ fpsyg.2016.01617.

Van Leeuwen, C., \& Lachmann, T. (2004). Negative and positive congruence effects in letters and shapes. Perception and Psychophysics, 66(6), 908-925. https://doi.org/10. 3758/BF03194984.

Witton, C., \& Talcott, J. B. (2018). Auditory processing in developmental dyslexia: Some considerations and challenges. In T. Lachmann \& T. Weis (Eds.), Reading and dyslexia: From basic functions to higher order cognition (pp. 135-146). Berlin: Springer International Publishing AG.

World Health Organization. (2019). International classification of diseases for mortality and morbidity statistics (11th ed.). Retrieved from https://icd.who.int/browse11/1-m/en.

World Literacy Foundation (2015). The economic and social cost of illiteracy. A snapshot of illiteracy in a global context. Retrieved from https://secureservercdn.net/160.153. 137.20/4ac.996.myftpupload.com/wp-content/uploads/ WLF-FINAL-ECONOMIC-REPORT.pdf.

Ziegler, J. C., Perry, C., \& Zorzi, M. (2014). Modelling reading development through phonological decoding and selfteaching: Implications for dyslexia. Philosophical Transactions of the Royal Society B, 369, 20120397.

Publisher's Note Springer Nature remains neutral with regard to jurisdictional claims in published maps and institutional affiliations. 